\title{
Fatal Rupture of a Giant Carotid Aneurysm Following High-flow Bypass and Endovascular Occlusion
}

\author{
Kyu Chang LEE, M.D., and Dong Ik KIM, M.D.*
}

\begin{abstract}
Summary : A case of fatal rupture of a giant internal carotid aneurysm is reported, which occurred after an extracranial to intracranial (EC-IC) bypass surgery combined with occlusion of the proximal internal carotid artery (ICA) by detachable balloons. A 65-year-old woman presented with progressive visual deterioration due to an unruptured giant aneurysm at the supraclinoid segment of the ICA. Since the patient did not tolerate a balloon occlusion test of the ICA, saphenous vein graft was undertaken between the proximal external caroid artery and the middle cerebral artery (MCA). Three balloons were placed in the proximal ICA to occlude the ICA six days after the surgery. Although no retrograde filling of the aneurysm from the MCA was seen on the postembolization angiography, a massive subarachnoid hemorrhage (SAH) occurred two days after the embolization. Changes of pressure and/or flow dynamics within the aneurysm induced by the high-flow bypass, and accompanying intramural hemorrhage might cause rupture of the giant aneurysm. It is believed that this complication may be avoided by using a normal-flow bypass with the graft diameter similar to that of the distal recipient artery. The aneurysm should be trapped immediately to prevent rupture, if there is any evidence of retrograde filling of the aneurysm following proximal occlusion.
\end{abstract}

\author{
Key words : \\ - giant aneurysm \\ - extracranial-intracranial \\ anastomosis \\ - saphenous vein graft \\ - carotid occlusion \\ - endovascular treatment
}

\section{Introduction}

Occlusion of the proximal parent artery is an accepted alternative treatment for unclippable aneurysms. ${ }^{611) 15)}$ It may be performed by surgical ligation, gradual clamp or detachable balloon. Extracranial to intracranial (EC-IC) bypass surgery has been used to increase the collateral reserve when collateral circulation is insufficient. ${ }^{17) 24)}$ Saphenous vein graft is especially useful when an adequate superficial temporal artery is not available or an immediate high flow is required. ${ }^{25)}$

Hemorrhagic complications occur very rarely after bypass surgery followed by carotid occlusion. ${ }^{110) 12) 1421)}$ In this report, rupture of an unruptured giant aneurysm at the ICA after balloon occlusion of the parent artery following an EC-IC high-flow bypass is presented. It is speculated that a change of blood flow pattern or increased intraaneurysmal pressure resulted from a high-flow bypass caused this unusual complication. The role of intramural hemorrhage in acutely thrombosed giant intracranial aneurysms should also be considered as an alternative explanation for the rupture. ${ }^{20) 22)}$

\section{Case Report}

A 65-year-old woman was admitted with a two-year history of a progressive visual disturbance. Her left eye became blind and vision decreased in her right eye from six months ago. She was also suffered from an intermittent frontal headache for ten years. Neurologic examination revealed left blindness, but she was able to count fingers at $50 \mathrm{~cm}$ distance with her right eye which showed temporal visual field defect. Bilateral optic disc atrophy, more severe on the left, was noted. A cranial computed tomographic (CT) scan and magnetic resonance imaging demonstrated a $2.5 \mathrm{~cm}$ sized aneurysm in the suprasellar region compressing the optic chiasm and the left optic nerve. There was no evidence of intramural thrombus formation or a SAH (Fig. 1). Right internal carotid angiography disclosed a giant aneurysm arising from

Departments of Neurosugery and * Diagnostic Radiology, Yonsei University College of Medicine, Seoul, Korea (Received 31 July, 1992) [Mailing address: Prof. Kyu Chang Lee, M.D., Department of Neurosurgery, Yonsei University College of Medicine, C.P.O. Box 8044, Seoul, 120-752, Korea] 
the supraclinoid segment of the ICA with a broad neck (Fig. 2). There was an irregular narrowing at the $\mathrm{M}_{1}$ segment of the left MCA, which was considered an atherosclerotic change (Fig. 3A). Cross compression study of the circle of Willis revealed an insufficient collateral through the anterior- and the posterior-communicating arteries. Under continuous monitoring of electroencephalography (EEG), test occlusion of the left ICA was performed with occlusion balloon catheter.* The patient became hemiplegic and aphasic immediately after inflation of balloon. Slowing (theta and delta waves) of EEG tracing was also noticed.

Since the superficial temporal artery and occipital artery were less than $1 \mathrm{~mm}$ in diameter, the saphenous vein graft was planned. Under general anesthesia, the saphenous vein was harvested from the right thigh. An interposition graft was done between the left external carotid artery and proximal $\mathrm{M}_{2}$ segment of the left MCA. This procedure was performed without systemic heparinization. Postoperatively, she remained neurologically intact, and the pulsation of the graft was very good.

Second angiography was done six days after the bypass surgery, and it showed a widely patent venous graft with good visualization of the left MCA. The size of the aneurysm was unchanged, but contrast layering was seen within the sac and the aneurysm was opacified much slowly. It was considered that the preferential flow to the aneurysm had changed from anterograde to retrograde inflow pattern through the bypass. The patient tolerated well during a 20 -minute test occlusion of the left ICA. A No. 16 Debrun latex balloon catheter attached to a Teflon coaxial catheter system was located in the left ICA just below the aneurysm. The balloon was detached after inflating it with water soluble contrast media. Second and third balloons were subsequently detached at the cervical segment of the ICA as a 'fail-safe' mechanism. A control angiogram showed the balloons in the destined position occluding the left ICA. Collateral circulation through the bypass did not show retrograde filling of the aneurysm (Fig. 3A, B).

During the immediate post-occlusion period, the patient was monitored closely in the neurosurgical intensive care unit. Low dose antiplatelet medication was given and systemic blood pressure was maintained at a slightly higher level than pretreatment

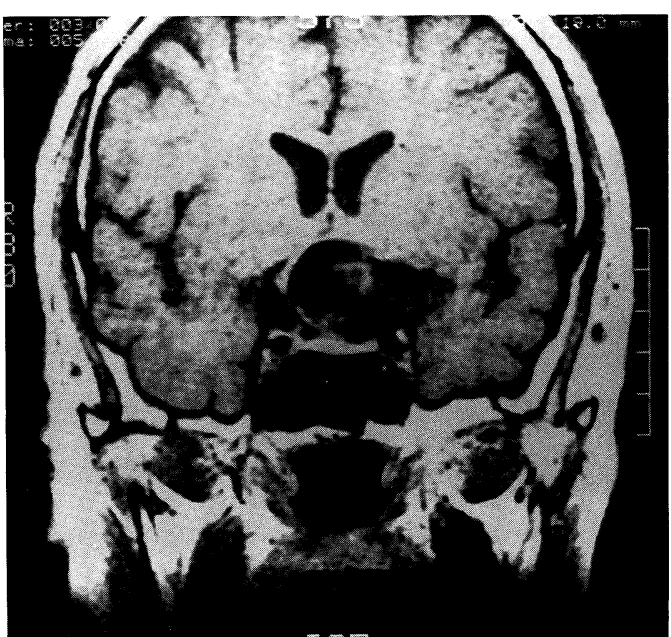

Fig. 1 Coronal $\mathrm{T}_{1}$-weighted MR image showing a round sac of aneurysm in the left side of suprasellar cistern. Focal high signal intensity within the sac of aneurysm suggests the turbulent flow. Note the absence of mural thrombus.

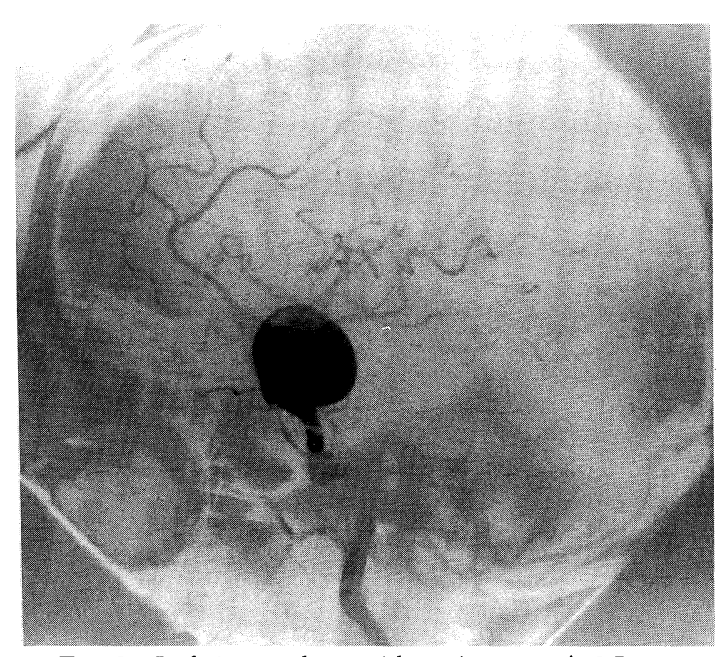

Fig. 2 Left internal carotid angiogram. A $2.5 \mathrm{~cm}$ sized giant aneurysm with a broad neck arises from the left internal carotid artery distal to the ophthalmic artery.

state. On the second post-occlusion day, she suddenly lapsed into stuporous state. A CT scan showed a massive SAH and acute dilatation of the ventricles. There was a sickle shaped high density hemorrhage in the wall of the aneurysm, which seemed to be the site of rupture (Fig. 4). An emergency ventricular drainage was done to reduce the intraventricular pressure below $20 \mathrm{mmHg}$. Despite aggressive medical treatment, the patient deteriorated rapidly into coma

*5F Double lumen occlusion balloon catheter manufactured by Medi-Tech Division, Cooper Scientific Co., Mass, U.S.A. 

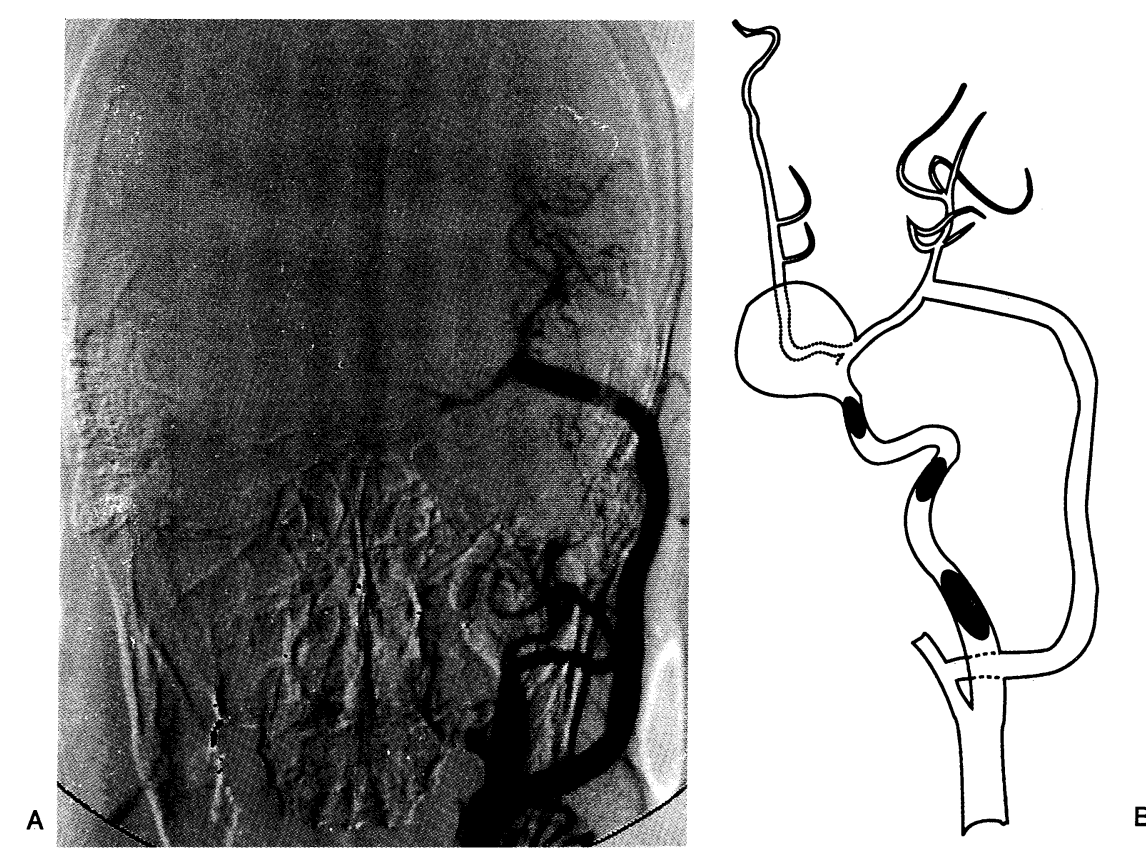

Fig. 3 Left common carotid angiogram following EC-IC bypass surgery and carotid occlusion with placement of three detachable balloons (A), and its schematic drawing (B).

and eventually died one week after the rupture.

\section{Discussion}

The ideal treatment for cerebral aneurysms is surgical clipping of the aneurysm neck. However, sometimes it may be difficult to clip the neck, especially in giant aneurysms, because of encroachment of the parent artery or splaying of branch vessel at the neck of aneurysm. The morbidity and mortality rates from direct surgical treatment of giant aneurysms range from 16 to $38 \%{ }^{6) 17) 25)}$ Abrupt or gradual occlusion of the parent artery has long been used for difficult cases to minimize the surgical complications. Stasis of blood flow and reduction of intraluminal pressure in the carotid artery distal to the occlusion would induce thrombosis of aneurysms and thereby reduce the incidence of subsequent rupture. ${ }^{8) 16) 27)}$ The incidence of bleeding after carotid ligation is reported to be less than $6 \% .{ }^{6) 16) 19)}$ Recently, most of surgical ligation and gradual clamp technique have been replaced with detachable balloon occlusion technique. Detachable balloon occlusion could be done while the patient is awake. The balloon is placed into the distal ICA using the Seldinger's intra-arterial catheter technique. ${ }^{2) 7) 233}$ Fox et al. reported that ten of 21 unclippable aneurysms of the carotid artery, situated between the origin of the ophthalmic artery and the carotid bifurcation, showed complete

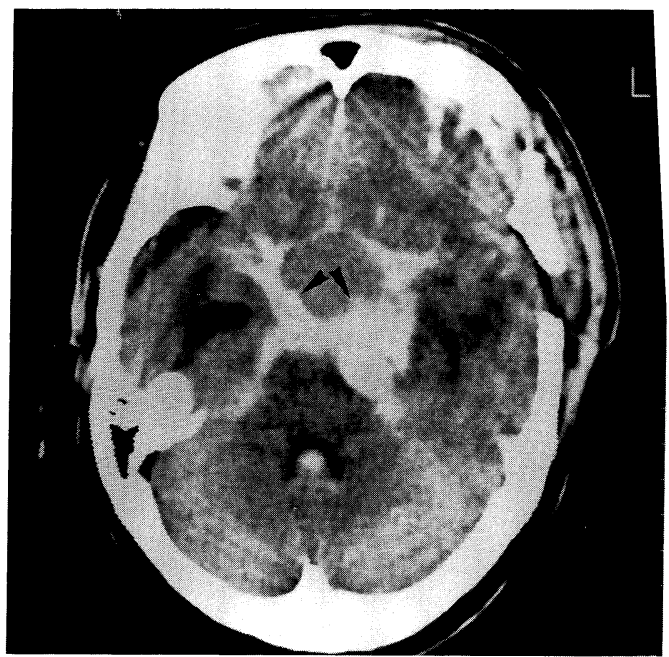

Fig. 4 Non-contrast CT scan on the day of rupture showing a massive $\mathrm{SAH}$. A crescent area of hyperdense mural hemorrhage is observed in the posterior wall of the aneurysm (small arrow heads). The size of the aneurysm sac has been slightly enlarged than pretreatment state and major portion of aneurysmal sac is not thrombosed at all.

aneurysm thrombosis on late follow-up angiograms. The other 11 cases required an additional intracranial trapping procedure to achieve complete aneurysm obliteration. $\left.{ }^{7}\right)$

This occlusion technique has limitations mainly 
due to the ischemic complications. The 1966 cooperative aneurysm study revealed the ischemic complications occurred in $59 \%$ after abrupt ICA occlusions and in $41 \%$ of the gradual ICA occlusions. ${ }^{16)}$ Most of such complications result from hypoperfusion with infarction, but emboli from the occlusion site or propagating thrombus are the other causes. Feasibility of occlusion of the carotid artery should be tested by temporary balloon occlusion while monitoring neurological functions and EEG. ${ }^{2)}$ If a patient does not tolerate the test occlusion of the carotid artery, concurrent EC-IC anastomosis has been used to improve distal circulation. But ischemic complications could not be prevented entirely even with this technique, because of the clot propagation from the site of the carotid occlusion and the embolization. ${ }^{3) 5) 11) 12)}$

Aneurysms of the ICA may enlarge after carotid occlusion. Most authors attributed such enlargement to a propagation of thrombosis in the aneurysmal sac. ${ }^{4) 10) 27)}$ But intramural or perimural localized hemorrhage with subsequent organization has also been pointed out for sudden aneurysmal enlargement. ${ }^{22)}$ It was postulated that the membrane and capillaries within the aneurysm wall behave like those of chronic subdural hematoma. For unknown reasons, in some cases, the sprouting capillaries rupture and cause recurrent intramembraneous hemorrhage. ${ }^{20)}$ This mechanism may be responsible for some of clinical worsening associated with acute aneurysmal thrombosis.

The continued enlargement and eventual rupture of giant aneurysms after carotid ligation and EC-IC bypass are rare. ${ }^{112) 14) 15) 21)}$ Hopkins and Grand reported that a patient with a previously unruptured giant aneurysm of supraclinoid ICA, who underwent a superficial temporal-MCA bypass, had a fatal rupture eight days after the bypass, before carotid ligation was accomplished. ${ }^{12)}$ Matsuda et al. and Anson et al. reported fatal rupture of unruptured giant carotid aneurysms after bypass surgery and carotid occlusion with a Selverstone clamp. ${ }^{114)}$ There was an angiographic evidence of retrograde filling of the aneurysm from the bypass graft in above cases. Aneurysmal rupture in these cases may be resulted from changes in flow pattern produced by EC-IC bypass ${ }^{1) 12(14) 18)}$ that might increase intraluminal pressure within the aneurysm, resulting in expansion and rupture.

Although postembolization angiogram did not demonstrate any retrograde inflow to the sac of aneurysm in our case, it ruptured on the second day. Expansion of the aneurysm sac with intramural hematoma seen on the CT scan immediately after the rupture may indicate the site of rupture. It was very peculiar that the aneurysm sac was not at all thrombosed on CT scan. We speculate that high-flow saphenous vein graft with much larger size may rerouted a retrograde flow into the aneurysm after induced mild hypertension during the post-occlusion period, and antiplatelet medication played a role in preventing thrombosis.

Thus, one reasonable solution to avoid such a complication is preparation of a venous graft with a caliber of same size to the recipient artery that will maintain the normal flow. If an aneurysm continues to be filled or enlarges over time after the carotid occlusion, an additional procedure to complete distal vessel occlusion or trapping of an aneurysm should be followed. A close neuroradiological follow-up is mandatory in all aneurysm patients treated by EC-IC bypass together with parent arterial occlusion.

The goal of occlusion treatment is to induce complete thrombosis of the aneurysm, and incomplete thrombosis will leave the aneurysm more vulnerable to rupture. Even with complete thrombosis no guarantee is offered against subsequent rupture. ${ }^{2628)}$ Therefore, direct clipping and decompression of a giant aneurysm would be the best treatment, but one must weigh the benefit from the surgery against the surgical morbidity and mortality. Bypass surgery combined with balloon occlusion may be the best current treatment for giant aneurysms that could not be clipped. However, further refinements are necessary in the treatment of unclippable giant aneurysms to avoid rare but dreadful rupture of the aneurysm after such treatment. The recent innovative endovascular treatments would be a very attractive approach, although these techniques are still under clinical study. ${ }^{9) 13)}$

Presented at the 21st Meeting of the Japanese Conference on Surgery for Cerebral Stroke on March 3, 1992 in Nagoya, Japan

\section{文献}

1) Anson JA, Stone JL, Crowell RM: Rupture of a giant carotid aneurysm after extracranial-to-intracranial bypass surgery. Neurosurgery 28: 142-146, 1991

2) Berenstein A, Ransohoff J, Kupersmith M, et al: Transvascular treatment of giant aneurysms of the cavernous carotid and vertebral arteries. Functional investigation and 
embolization. Surg Neurol 21: 3-21, 1984

3) Collice M, Arena O, Fontana RA: Superficial temporal artery to proximal middle cerebral artery anastomosis: Clinical and angiographic long-term results. Neurosurgery 19: 992-997, 1986

4) Cuatico W, Cook AW, Tyshchenko V, et al: Massive enlargement of intracranial aneurysms following carotid ligation. Arch Neurol 17: 609-613, 1967

5) Diaz FG, Ausman JI, Pearce JE: Ischemic complications after combined internal carotid artery occlusion and extracranial-intracranial anastomosis. Neurosurgery 10: 563-570, 1982

6) Drake CG: Giant intracranial aneurysms: Experience with surgical treatment in 174 patients. Clin Neurosurg 26: 1295, 1979

7) Fox AJ, Vinuela F, Pelz DM, et al: Use of detachable balloons for proximal artery occlusion in the treatment of unclippable cerebral aneurysms. J Neurosurg 66: 40-46, 1987

8) Galbraith JG, Clark RM: Role of carotid ligation in the management of internal carotid aneurysms. Clin Neurosurg 21: $171-181,1974$

9) Guglielmi G, Vinuela F, Dion J, et al: Electrothrombosis of saccular aneurysm via endovascular approach, Part 2: Preliminary clinical experience. J Neurosurg 75: 8-14, 1991

10) Heros RC, Ameri AM: Rupture of a giant basilar aneurysm after saphenous vein interposition graft to the posterior cerebral artery. Case report. J Neurosurg 61: 387-390, 1984

11) Heros RC, Nelson PB, Ojemann RG, et al: Large and giant paraclinoid aneurysms: Surgical techniques, complications and results. Neurosurgery 13: 153-163, 1983

12) Hopkins LN, Grand W: Extracranial-intracranial arterial bypass in the treatment of aneurysms of the carotid and middle cerebral arteries. Neurosurgery 5: 21-31, 1979

13) Knuckey NW, Haas R, Jenkins R, et al: Thrombosis of difficult intracranial aneurysms by the endovascular placement of platinum-Dacron microcoils. J Neurosurg 77: 4350, 1992

14) Matsuda M, Shiino A, Handa J: Rupture of previously unruptured giant carotid aneurysm after superficial temporalmiddle cerebral artery bypass and internal carotid occlusion. Neurosurgery 16: 177-184, 1985

15) Morgan $M$, Besser $M$, Dorsch $N$, et al: Treatment of intracranial aneurysms by combined proximal ligation and extracranial-intracranial bypass with vein graft. Surg Neurol 26: 85-91, 1986
16) Nishioka H: Report on the Cooperative Study of Intracranial Aneurysms and Subarachnoid Hemorrhage: Section III, Part 1. Results of the treatment of intracranial aneurysms by occlusion of the carotid artery in the neck. J Neurosurg 25: 660-682, 1966

17) Onuma T, Suzuki J: Surgical treatment of giant intracranial aneurysms. J Neurosurg 51: 33-36, 1979

18) Prolo DJ: Comment on Hopkins LN, Grand W: Extracranial-intracranial arterial bypass in the treatment of aneurysms of the carotid and middle cerebral arteries. Neurosurgery 5: 30-31, 1979

19) Roski RA, Spetzler RF, Nulsen FE: Late complications of carotid ligation in the treatment of intracranial aneurysms. J Neurosurg 54: 583-587, 1981

20) Schubiger O, Valavanis A, Wichmann W: Growth mechanism of giant intracranial aneurysms; Demonstration by CT and MR imaging. Neuroradiology 29: 266-271, 1987

21) Scott RM, Liu HC, Yuan R, et al: Rupture of a previously unruptured giant middle cerebral artery aneurysm after extracranial-intracranial bypass surgery. Neurosurgery 10: 600-603, 1982

22) Sekhar LN, Heros RC: Origin, growth, and rupture of saccular aneurysms: A review. Neurosurgery 8: $248-260$, 1981

23) Serbinenko FA, Filatov JM, Spallone A, et al: Management of giant intracranial ICA aneurysms with combined extracraninal-intracranial anastomoses and endovascular occlusion. J Neurosurg 73: 57-63, 1990

24) Spetzler RF, Schuster H, Roski RA: Elective extracranialintracranial arterial bypass in the treatment of inoperable giant aneurysms of the internal carotid artery. J Neurosurg 53: 22-27, 1980

25) Sundt TM Jr, Piepgras DG: Surgical approach to giant intracranial aneurysms. Operative experience with 80 cases. J Neurosurg 51: 731-742, 1979

26) Swearingen B, Heros RC: Fatal rupture of a thrombosed giant basilar artery aneurysm. Surg Neurol 23: 299-302, 1985

27) Tindall GT, Goree JA, Lee JF, et al: Effect of common carotid ligation on size of internal carotid aneurysms and distal intracarotid and retinal artery pressure. J Neurosurg 25: 503-511, 1966

28) Whittle IR, Dorsch NW, Besser M: Spontaneous thrombosis in giant intracranial aneurysms. J Neurol Neurosurg Psychiatry 45: 1040-1047, 1982 